\title{
Bloodshed will not stop in a constantly reinforced conflict
}

\author{
Tam-Tri Le \\ Centre for Interdisciplinary Social Research \\ Phenikaa University, Hanoi, Vietnam \\ Written in Ho Chi Minh city, on 27 August 2021
}

Just as the world has expressed concerns recently, a terrorist attack actually did happen following the current chaotic situation in Afghanistan. On August $26^{\text {th }} 2021$, suicide bombers attacked near Kabul airport, killing dozens of Afghan civilians and 13 service members from the United States (Aikins et al., 2021). U.S. President Joe Biden immediately condemned the attack, stating clearly that "[...] We will not forgive. We will not forget. We will hunt you down and make you pay" (Shear, 2021).

It has been said countless times, that violence will only lead to more violence; and they - from all sides involved in these conflicts - are well-aware of this saying of bitter wisdom, but are they capable enough to carry out the alternative(s)? A vicious cycle stemming from deep-rooted distrust needs to be replaced by a systematic, integral, and long-term approach. It is impossible to kill all your enemies. They are people who have close connections with other people (and dare I say, in a globalized world!). Eliminating threats by brute force will potentially create more threats for the next generations (or in this quickly changing world - probably next-year, or even nextweek revenge, and maybe much closer to your doorstep).

Humanity has enough resources (both physical and mental) to build a sustainable global security program. The rather ineffective and extremely costly counterterrorist operations so far have proved that capacity, we just need some adjustments in direction, and importantly, collaboration. New insights on the psycho-religious mechanism of suicide, trust, and radicalization (Vuong et al., 2021) can help anyone get a better grasp on the overall situation and the psychology involved.

Murder is horrible no matter how one tries to justify it. Grief will rightfully follow. But putting the horror to an end is human morality. Constantly reinforcing the killing cycle is a shame for a being with free-will and sympathy.

\section{References}

Aikins, M., Hassan, S., Gibbons-Neff, T., Schmitt, E., \& Pérez-Peña, R. (2021, August 26). Suicide Bombers in Kabul Kill Dozens, Including 13 U.S. Troops. The New York Times. https://www.nytimes.com/2021/08/26/world/asia/kabul-airport-bombing.html

Shear, M. (2021, August 26). President Biden condemns terrorist attack and vows to hunt down those responsible. The New York Times. https://www.nytimes.com/2021/08/26/world/biden-afghanistan-kabul-airport-attack.html

Vuong, Q.-H., Nguyen, M.-H., \& Le, T.-T. (2021). A Mindsponge-Based Investigation into the Psycho-Religious Mechanism Behind Suicide Attacks. Sciendo. https://doi.org/10.2478/9788366675599 